\title{
Playware ABC 2: a Disruptive Technology for Global Development
}

\author{
Henrik Hautop Lund \\ Center for Playware, Technical University of Denmark, Building 326, 2800 Kgs. Lyngby, Denmark \\ E-mail: hhl@playware.dtu.dk \\ www.playware.elektro.dtu.dk
}

\begin{abstract}
The Playware $\mathrm{ABC}$ concept is used to create solutions that are usable by all kinds of users and contexts in our globalized society. In this paper, the Playware $\mathrm{ABC}$ can be exemplified with the development of the modular interactive tiles for health prevention and rehabilitation of anybody, anywhere, anytime. The paper gives examples of how playware becomes a disruptive technology for global development, for instance in the health sector. For instance, in Tanzania doctors and community-based rehabilitation workers are constructing and combining modular playware tiles to easily create the right kind of intervention for their patients in both urban and deep rural areas in Tanzania.
\end{abstract}

Keywords: Playware, user-friendly, modularity, development, playful robotics and intelligent systems.

\section{Introduction}

We outlined in [1] that when people get into playdynamics, there can be certain effects of play which we termed the collateral effects of play. The collateral effects of play can be educational achievements, motor skill enhancement, cognitive and physical rehabilitation, etc. In the following, we will exemplify such collateral effects of play in the area of health [2].

If it is true that the collateral effects of play on playware may lead to significant and important health improvements, then it also becomes mandatory to investigate the engineering principles, which may facilitate a distribution of playware to everybody regardless of their skills, societal context, etc. We address this issue with the Playware $A B C$ concept, which is based on:
A: Anybody, Anywhere, Anytime
B: Building Bodies and Brains
$\mathrm{C}$ : Construct, Combine, Create

Indeed, the Playware $\mathrm{ABC}$ concepts works for creating technology solutions for anybody, anywhere, anytime by using embodied artificial intelligence building bodies and brains, which facilitates that users can themselves manipulate with the technology solutions to construct, combine and create their own solutions.

\section{Moto tiles for Health}

The Playware ABC can be exemplified with the development of the modular interactive tiles for health prevention and rehabilitation of anybody, anywhere, anytime. In this context, play as a free and voluntary activity, which is performed for the personal enjoyment, may result in highly motivated patients, if the technology can mediate such playful engagement. At the same time, it may be possible to observe the collateral effects of play in the form of quantifiable health effects that exceeds the effects measured with traditional health intervention methods $[2,3]$. 
Therefore, based on the Playware ABC, we developed modular playware in the form of the modular interactive tiles, now called Moto tiles (www.mototiles.com). The Moto tiles activates the user to perform playful interaction with play and games on the tiles that light up in different colors and registers when users step on them.

These Moto tiles are based on various generations of prototypes of modular interactive tiles, which we developed over the last decade $[4,5]$. Each tile has a ring of 8 RGB LEDs, a sensory system to register step on the top surface, its own processor and rechargeable lithium battery. As a consequence of the design based on the Playware ABC concept, these Moto tiles can be easily transported to be set-up and used anywhere within a minute.

The new Moto tiles are connected to a tablet with the ANT + radio protocol. On the tablet, the user can select between numerous games that challenge both the physical and cognitive abilities of the user. Further, the tablet shows the score in each games, shows statistics for the user, and make automatic documentation of

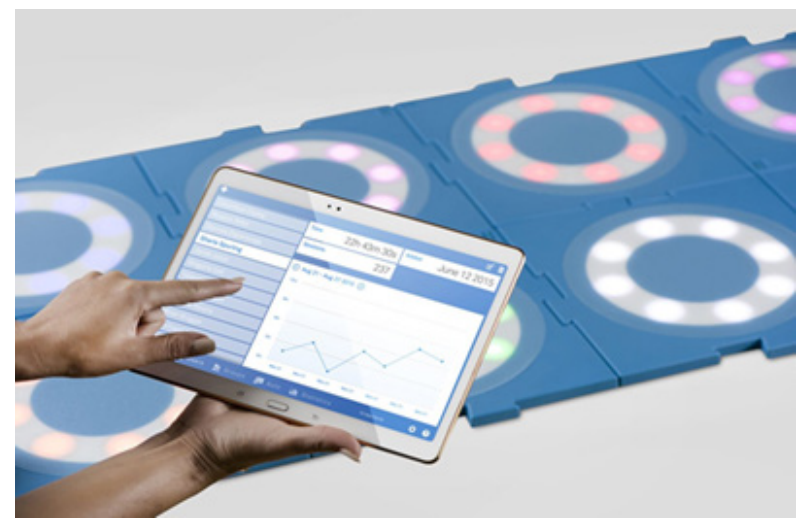

effect.

Fig. 1. Moto tiles and app interface (www.mototiles.com)

Scientific studies of effect among community-dwelling elderly who perform group play on the modular tiles once per week show highly statistical significant effect on functional abilities of the elderly. Especially, the balancing abilities of the elderly (avg. 83 years of age) increase by more than $60 \%$ after merely 13 training sessions [3]. Also, all other measured functional abilities (strength, mobility, agility, and endurance of the elderly) improved with statistical significant effect.
Qualitative studies suggest that the high health effect from playing with the Moto tiles arises since the Moto tiles act as a play force, which pushes the participants into a play-dynamics, in which they forget about time and place, and thereby perform more than they would normally do. In play, they may forget about their fears of falling and forget about their perceived physical and cognitive limitations.

With such quantifiable health effect results of play, playware technology may disrupt certain areas of the health sector. Already, the Moto tiles are used in the health sector for the benefit of cardiac patients, stroke patients, elderly citizens at risk of falling, dementia patients, children with cerebral palsy, and in special schools in three continents. This disruptive technology for the health sector is a result of the Playware ABC with the possibility for the end-user to easily adapt to different tasks and practices, e.g. for different kinds of patients.

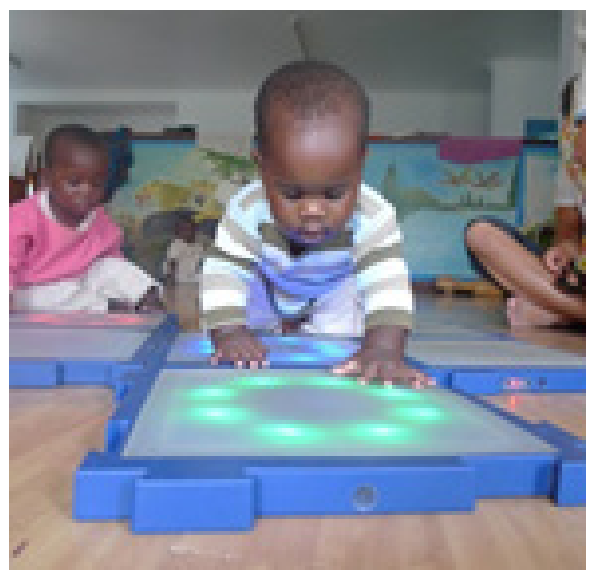

Fig 2. Modular interactive tiles for rehabilitation of mentally and physically handicapped children in Tanzania.

Indeed, the modular interactive tiles can be used by anybody, anywhere, anytime, as it does not demand any particular knowledge of the user, and it does not demand any infrastructure. Hence, it is used as a playful technology solutions for rehabilitation of children with cerebral palsy, mental retardation, etc. in deep rural subSaharan Africa [6, 7]. This derives from the Playware $\mathrm{ABC}$, which here results in a highly mobile, modular and energy efficient technology, which can be set up and used anywhere and anytime. In Tanzania, we are forming a national partnership for sustainable implementation, comprising a governmental 
representative, national hospital, national health university department, regional hospitals, Living Labs and NGOs performing community-based rehabilitation.

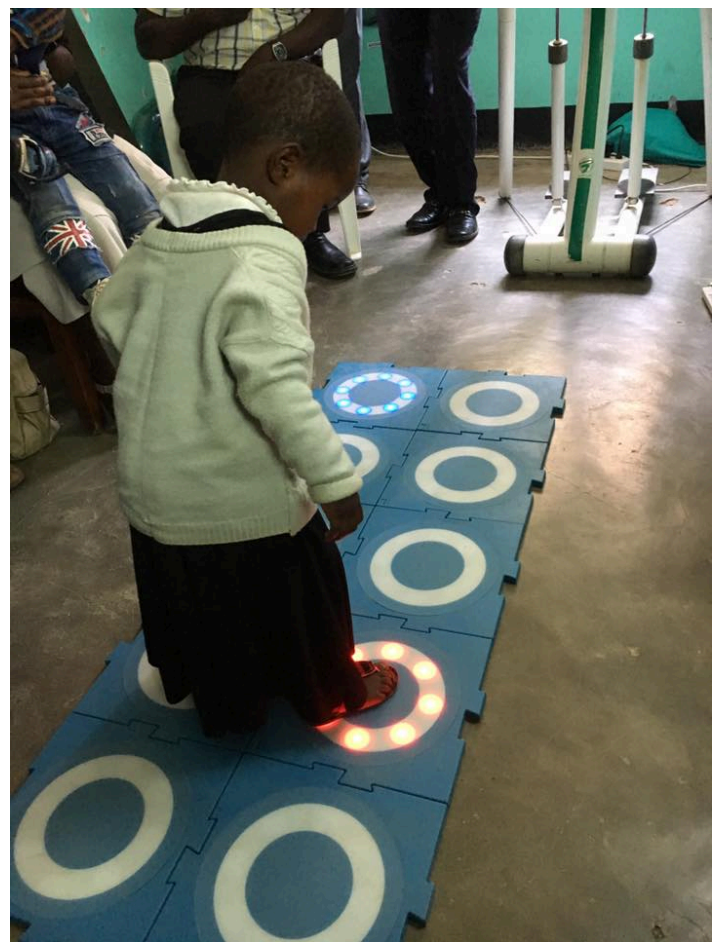

Fig. 3. Playful rehab of meningitis affected child in Iringa Regional Hospital, Tanzania.

The users such as doctors in the hospitals or health workers in community-based rehabilitation programs are constructing and combining the modular tiles to easily create the right kind of intervention for their patients. The battery-powered tiles present a vast number of opportunities for games and can be used for many different purposes. Due to the modularity, it is very easy to co-design and adapt the modular tiles system to different contexts, different intervention areas, and different levels of competencies.

This can have an important impact in rehabilitation of disabled, stroke, and cardiac patients in parts of the world where a large part of the population lives in remote and rural areas. Here, potential health technology solutions often face problems of scarce availability of electricity, of technology professionals, and of health personnel. Further, due to the relatively low amount of health spendings and of health workers e.g. in sub-Saharan Africa compared to high-income countries, the individual health worker will typically need to treat a vast array of health problems compared to the high degree of specialization to single health problems amongst health workers in high-income countries. Hence, to be effective in low-income regions such as sub-Saharan Africa, there is a need for health technology solutions, which facilitate treatment of people with various diagnoses.

Through the Playware ABC, we address this challenge with the modular interactive tiles, which aim at motivating patients to perform rehabilitative actions. By taking advantage of the flexibility and easy approach to personalization inherent in the modularity, the proposed modular approach possesses the potential of becoming particularly helpful in addressing both the technological challenges and health challenges in low-income communities. With the high prevalence of disability, stroke and coronary heart cases in sub-Saharan Africa countries, it is of paramount importance to investigate how this kind of an approach can provide an eHealth solution flexible enough to adapt to the needs of patients. Based on the Playware $\mathrm{ABC}$, we therefore aim at refining and contextualising modular interactive tiles to allow a local community to have one modular solution that any community rehabilitation worker can easily adapt to the individual patient and his/her needs.
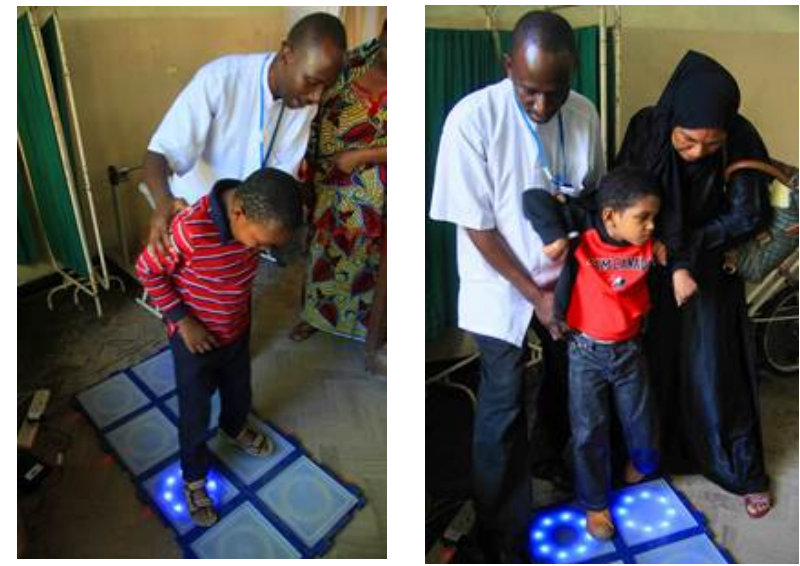

Fig. 4. Modular interactive tiles for rehabilitation at Muhimbili National Hospital, Dar Es-Salaam, Tanzania. 


\section{Conclusion}

We developed the modular interactive tiles as an exemplification of Playware $\mathrm{ABC}$ to allow anybody, anywhere, anytime to be building bodies and brains, which facilitates users to construct, combine and create. Indeed, in health institutions in Sub-Saharan Africa, doctors and health care workers are now utilizing the modular interactive tiles for a variety of interventions for mentally disabled children, elderly stroke patients, etc.

In future, we will investigate further the adaptation, contextualisation and implementation of such Playware $\mathrm{ABC}$ derived technology solutions in different contexts, including in areas of development. Especially for the health area, we will investigate with different rehabilitation methods and centres, including hospitals both in a city centres and in a rural area, NGO's performing community based rehabilitation, and rehabilitation centres [6].

\section{Acknowledgements}

The author would like to thank colleagues at the Center for Playware, Technical University of Denmark.

\section{References}

1. H. H. Lund, "Playware ABC: Engineering Play for Everybody" ibid.

2. H. H. Lund, "Play for the Elderly - Effect Studies of Playful Technology," in Human Aspects of IT for the Aged Population. Design for Everyday Life. (LNCS Vol. 9194, pp 500-511, Springer-Verlag, 2015)

3. H. H. Lund, and J. D. Jessen, "Effects of short-term training of community-dwelling elderly with modular interactive tiles," GAMES FOR HEALTH: Research, Development, and Clinical Applications, 3(5), 277-283, 2014.

4. H.H. Lund, T. Klitbo, and C. Jessen, "Playware Technology for Physically Activating Play", Artificial Life and Robotics Journal, 9:4, 165-174, 2005

5. H. H. Lund "Modular Robotics for Playful Physiotherapy", in Proceedings of IEEE International Conference on Rehabilitation Robotics (IEEE Press, 571 575,2009 ).

6. H. H. Lund, L. S. D. Jensen, Y. Ssessanga, S. Cataldo \& K. I. Yahya-Malima, "An Approach for a National eHealth Implementation - the Case of Modular Interactive Tiles for Rehabilitation," in P Cunningham \& $M$ Cunningham (eds), IST-Africa 2015 Conference Proceedings, 10.1109/istafrica.2015.7190552.

7. H. H. Lund, L.S.D. Jensen, Y. Ssessanga, R. Abdalahman. "Implementing Modular Interactive Tiles for Rehabilitation in Tanzania - a Pilot Study", in ISTAfrica 2014 Conference Proceedings, P Cunningham and $\mathrm{M}$ Cunningham (Eds), IIMC International Information Management Corporation, 2014, ISBN: 978-1-90582443-4. 